\title{
DOCÊNCIA NA UNIVERSIDADE PÚBLICA: A SAÚDE DOS \\ TRABALHADORES DA EDUCAÇÃO
}

Franciele Ariene Lopes Santana

Universidade Federal de Mato Grosso do Sul

Ilidio Roda Neves

Universidade Federal de Mato Grosso do Sul
Recebido em: 28/09/2019

$1^{\text {a }}$ revisão em: $14 / 02 / 2020$

Aceito em: 27/05/2020

\section{RESUMO}

Este estudo aborda a saúde docente na educação superior pública brasileira. Objetivou-se, por meio de revisão integrativa da literatura: (1) analisar a relação entre situações de trabalho e possível desgaste na saúde; (2) levantar tipos frequentes de adoecimento em docentes descritos nas publicações; e (3) descrever e analisar as cargas de trabalho relatadas. Cruzando descritores, buscaram-se produções científicas em dez bases de dados. Foram encontradas 2.892 publicações, das quais apenas 76 se enquadravam dentro dos critérios de seleção. O desgaste foi manifesto, sendo com maior frequência de problemas psíquicos ligados às cargas internas de trabalho como pressão por produtividade. As situações de trabalho relatadas nas experiências subjetivas frente às condições, gestão, política econômico-social e reestruturação da universidade, permeadas pelo produtivismo e sobrecarga, evidenciam importante relação das situações de trabalho e no adoecimento e desgaste laboral.

Palavras-chave: condições de trabalho; professores universitários; licença médica. 


\title{
TEACHING AT PUBLIC UNIVERSITIES: THE HEALTH OF EDUCATION WORKERS
}

\author{
ABSTRACT
}

The object of interest in the paper was the health of Brazilian public higher education teachers. The methodology applied was Integrative Review, with the objectives: 1) to analyze the relationship between the labor situations and their possible consequence on health conditions; 2 ) to survey the illnesses that have been detected; 3) to describe workloads, based on those publications. The scientific studies were investigated by crossing some related descriptors in ten databases. The survey identified 2,892 publications, 76 fit the selection criteria. The most frequent problems were related to psychological issues, linked to workloads. The labor situations expressed in subjective experiences reported in terms of conditions, management, social-economic policies and University restructuring, permeated by productivism and work overload, proved to be determinant in illnesses and weariness.

Keywords: occupational health; working conditions; sick leave; professor.

\section{DOCENCIA EN LA UNIVERSIDAD PÚBLICA: LA SALUD DE LOS TRABAJADORES DE LA EDUCACIÓN}

\section{RESUMEN}

Este estudio aborda la salud del docente en la Educación Superior Pública Brasileña. Se colocó como objetivos por medio de la revisión integral de la literatura: (1) analizar la relación entre situaciones de trabajo y posible desgaste en la salud. (2) levantar tipos frecuentes de enfermedad en docentes descritos en las publicaciones; y (3) describir y analizar las cargas de trabajo relatadas. Cruzando descriptores, se buscaron producciones científicas en 10 bases de datos. Fueron encontradas 2.892 publicaciones, de las cuales apenas 76 coinciden en los criterios de selección. El desgaste fue manifiesto siendo con mayor frecuencia de problemas psíquicos relacionados a las cargas internas de trabajo como presión por productividad. El desgaste y las enfermedades expuestos frente a las condiciones, la gestión política económico- social y reestructuración de la Universidad, penetrada todavía, por el productivismo y la sobrecarga, presentadas por los estudios, refuerzan las relaciones entre las situaciones de trabajo actual y el desgaste laboral.

Palabras clave: enfermedad del profesor; situaciones de trabajo; salud del trabajador. 


\section{INTRODUÇÃO}

Este estudo propõe a investigar e analisar a relação entre as situações de trabalho e o desgaste docente nas Instituições Públicas de Educação Superior (IPES) brasileiras, partindo de estudos sobre o adoecimento docente, secundariamente, levantar os tipos mais frequentes de adoecimento em docentes de IPES que têm sido descritos nas publicações que abordam a temática, e, descrever e analisar, nas publicações, os possíveis registros de cargas de trabalho docente. Para fazer relação com o binômio saúde-doença, partiu-se da concepção que considera os cruzamentos existentes entre o sistema educacional e o sistema produtivo, entendendo que a organização desse último costuma orientar as demais relações estabelecidas pela sociedade (Corrêa \& Pimenta, 2014; Paparelli, 2010; Sguissardi \& Silva Júnior, 2009).

Destarte, faz-se necessário que a ciência se ocupe de investigar sobre como as situações de trabalho imprimem as suas marcas no processo saúde/ adoecimento das pessoas que desenvolvem sua vida em espaços laborais. A expressão "situação de trabalho", adotada aqui, denomina complexos elementos que constituem o trabalho, como "(...) as condições físicas, químicas e biológicas do ambiente de trabalho; os aspectos técnicos; a organização prescrita do trabalho, a organização real das atividades de trabalho, bem como a gestão destas, a caracterização dos canais formais de comunicação e das relações interpessoais" (Seligmann-Silva, 2011, p. 255). Assim sendo, para compreender os fenômenos que envolvem a saúde, trabalho e adoecimento docente no espaço da educação superior pública, analisou-se os fenômenos encontrados sob a ótica do conceito de trabalho na perspectiva marxista (Marx, 1996); da função psicológica do trabalho e coletivos profissionais de Clot (2007; 2010); a noção de desgaste biopsíquico e cargas de trabalho de Laurell e Noriega (1989); e, de desgaste mental decorrente do trabalho de Seligmann-Silva (2011).

\section{MÉTODO}

Realizou-se uma Revisão Integrativa de Literatura (RIL). Esse tipo de pesquisa pertence ao grupo de revisões que avalia e sintetiza conteúdos. Uma RIL objetiva localizar e integrar inferências relacionadas aos resultados de pesquisas sobre determinado tema para apresentar a situação conhecimento sobre a questão específica, ou possibilitar novas visões e problemas relacionados ainda não solucionados (Ursi, 2005).

Foram desenvolvidas as etapas da RIL propostas por Ganong (1987), citada por Botelho, Cunha e Macedo (2011), conforme exposto a seguir:

$\mathrm{Na} 1^{\text {a }}$ etapa definiram-se: a) estratégias de busca (publicações nacionais e internacionais com a temática da saúde docente de universidades públicas brasileiras); b) descritores: foi realizada a observação de palavras-chave em 
comum nos estudos levantados inicialmente sobre o tema, bem como investigação de termos de Ciências da Saúde/Medical Subject Headings (DeCS/MeSH) na Biblioteca Virtual em Saúde (BVS-MS/BIREME), sendo selecionados os seguintes descritores: Condições de Trabalho; Licença Médica; Ambiente de trabalho; Docente; Professor; Professores Universitários; Sick leave; Occupational Health; Working Conditions.

Acrescentou-se a estes, outros não indexados no DECS para precisar a relação entre o adoecimento e a universidade, uma vez que as terminologias da BVS foram muito generalistas. Agregou-se, então, os seguintes unitermos: Mal- estar; Adoecimento Docente; Professor Universitário; Docente Universitário; Universidade Federal; Universidade Pública; Malaise Teacher; Occupational Disease; Work Environment; University; Sickening/ Sickeness/IIIness Professor; Brazil. Optou-se por utilizar um maior número de descritores, pois, em busca exploratória com poucos termos, houve dificuldade de encontrar publicações que apresentassem relação com o universo de estudo.

Ainda nesta etapa as bases de dados foram definidas: 1) Periódicos da Capes; 2) Medline/ Pubmed (Medical Literature Analysis and Retrieval System Online Sistema Online de Busca e Análise de Literatura Médica); 3) BVS-PSI (Periódicos em Psicologia - Pepsic ); 4) Red de Revistas Científicas de América Latina y el Caribe, España y Portugal (Redalyc); 5) Banco de Teses e Dissertações da Capes; 6) Bireme - Biblioteca Regional de Medicina e Ciências da Saúde (Literatura LatinoAmericana e do Caribe em Ciências da Saúde - Lilacs); 7) Biblioteca Digital Brasileira de Teses e Dissertações - Instituto Brasileiro de Informações em Ciência e Tecnologia (BDTD-IBICT); 8) Banco de dados de resumos e citações de artigos Scopus e 9) Anais das reuniões da Associação Nacional de Pós-Graduação e Pesquisa em Educação - ANPED (Grupos de Trabalho-GT: 09 - Trabalho e Educação; 11 - Política de Educação Superior e 20 - Psicologia e educação); e, 10) Portal Brasileiro de publicações científicas em acesso aberto - Instituto Brasileiro de Informações em Ciência e Tecnologia (OASISBR-IBICT).

$\mathrm{Na} 2^{a}$ etapa ocorreu a construção dos critérios de inclusão e exclusão: excluídos estudos com professores do ensino infantil, básico, médio, de Institutos Federais (quando o foco era a educação técnica ou o ensino médio) e de universidades privadas, comunitárias e municipais. Para inclusão considerou-se publicações em língua portuguesa ou inglesa, desde que relacionada à questão do adoecimento de professores de IPES.

Foi definido um recorte temporal de 20 anos, elegendo-se o período de 1996 a 2016. O ano de 1996 foi escolhido pela promulgação da Lei $n^{\circ} 9.394$, Lei de Diretrizes e Bases da Educação - LDB (Presidência da República, 1996), que prevê a organização do ensino superior no país, descrevendo em seu art. 67 como os sistemas de ensino devem promover a valorização dos profissionais da educação: a) ingresso por concurso público; b) aperfeiçoamento profissional continuado (prevendo licenciamento periódico remunerado para tal); c) piso salarial 
profissional; d) progressão funcional (por titulação ou habilitação e avaliação), e) período reservado a estudos, planejamento e avaliação, incluído na carga de trabalho, e, f) condições adequadas de trabalho.

Partiu-se, então, para a $3^{a}$ etapa na qual se procedeu à identificação das publicações pré-selecionadas, com a leitura dos títulos das publicações, das palavras-chave, e de todos os resumos. Em algumas situações, devido ao resumo não conter todas as informações necessárias, foi realizada a leitura de parte dos estudos para que os critérios pudessem se aplicados.

$\mathrm{Na} 4^{a}$ etapa, com a categorização dos estudos selecionados, foram lidos os textos integralmente e as informações obtidas foram sumariadas por meio da adaptação do instrumento para desenvolvimento de Revisão Integrativa, validado por Ursi (2005). Configura-se em uma tabela de levantamento de dados bibliográficos composta pelos seguintes elementos: Identificação (tipo de produção; título; periódico; autor; ano; região geográfica de realização e publicação; instituição sede do estudo; e, área/campo do estudo); Características metodológicas do estudo (abordagem metodológica e objetivos); Resultados (aqui considerou-se em todos os estudos registros de: 1) situações de trabalho que poderiam levar ao sofrimento/adoecimento; 2) intervenção de Programa de Assistência à Saúde do trabalhador; e, 3) descrição direta de sofrimento/adoecimento); Conclusões, e, Rigor Metodológico aplicado.

Feita a sumarização de cada publicação, partiu-se para $5^{a}$ etapa na qual foi realizado o agrupamento de informações semelhantes em planilha do Excel, procedeu-se a análise e interpretação do material, com a discussão dos elementos obtidos e categorizados, iniciou-se a $6^{a}$ etapa: síntese dos achados.

\section{RESULTADOS}

Efetuou-se 92 tipos de combinações com os descritores elencados, cessando as buscas quando as publicações começaram a se repetir, encontrou-se 2.892 textos. Após a categorização, chegou-se a 76 trabalhos acadêmicos: 5 teses de doutorado, 23 dissertações de mestrado e 48 artigos, contemplando publicações tanto de pesquisas de campo, como estudos teóricos e revisões de literatura.

Na Tabela 1 é possível observar quais as áreas desenvolveram os estudos analisados. A maior parte foi realizada no campo da Educação, Psicologia, Enfermagem e Saúde, respectivamente. Para chegar a tais resultados considerouse a área de concentração dos programas de pós-graduação aos quais estavam vinculadas as teses e dissertações incluídas e, no que se refere aos artigos considerou-se a área de formação dos autores, o departamento de vinculação e/ou a possível descrição do campo de interesse que porventura tenha aparecido no corpo do texto. 
Tabela 1.

Estudos por área científica

\begin{tabular}{c|c|c} 
Área/Campo de estudo & Total & $\%$ \\
Educação & 17 & 22,3 \\
Psicologia & 14 & 18,4 \\
Enfermagem & 13 & 17,1 \\
Saúde & 11 & 14,4 \\
Multidisciplinar & 6 & 7,8 \\
Engenharias e Ambiente & 5 & 6,5 \\
Administração & 5 & 6,5 \\
Ciências Sociais & 3 & 3,9 \\
Fonoaudiologia & 1 & 1,3 \\
Serviço social & 1 & 1,3 \\
TOTAL & 76 & 100 \\
\hline
\end{tabular}

Na Tabela 2 estão expostos os textos que foram selecionados para a análise. Para facilitar a retomada dos textos analisados, apenas nos resultados adotar-se-á o número da publicação conforme disposto a seguir. $O$ critério adotado para disposição na tabela foi o de organização por ordem alfabética dos nomes dos autores. Na coluna "Tipo", utilizou-se as abreviações: "A" - Artigo; "D" Dissertação; "T" - Tese.

\section{Tabela 2.}

Publicações incluídas para análise ${ }^{1}$

\begin{tabular}{l|l|l|l} 
No & Autor(a)/Ano & Tipo & Título
\end{tabular}

1. Albuquerque (2013) D Relação entre condições de trabalho e Saúde vocal de professores no ensino superior

2. Alves (2007) D Parâmetros vocais e percepção vocal de professores universitários

3. Andrade (2014) D Trabalho docente e saúde ocupacional na Universidade Federal de Uberlândia

4. Araújo (2012) D Afastamento do trabalho: absenteísmo e presenteísmo em uma instituição federal de ensino superior 
Tabela 2. Continuação.

\begin{tabular}{|c|c|c|c|}
\hline $\mathbf{N}^{\circ}$ & Autor(a)/Ano & Tipo & Título \\
\hline 5. & Araújo (2013) & $\mathrm{D}$ & $\begin{array}{c}\text { A nova geração de professores } \\
\text { universitários: profissionalização, } \\
\text { condições de trabalho e sua relação com } \\
\text { a produtividade científica na UFRGS }\end{array}$ \\
\hline 6. & $\begin{array}{l}\text { Araújo \& Martins } \\
\qquad(2009)\end{array}$ & $A$ & $\begin{array}{c}\text { Condições de trabalho docente e saúde } \\
\text { na Bahia: estudos epidemiológicos }\end{array}$ \\
\hline 7. & Araújo et al. (2005) & D & $\begin{array}{l}\text { Mal-estar docente: avaliação de } \\
\text { condições de trabalho e saúde em uma } \\
\text { instituição de ensino superior }\end{array}$ \\
\hline 8. & Arbex et al. (2013) & $A$ & $\begin{array}{c}\text { Trabalho docente, readaptação e saúde: } \\
\text { a experiência dos professores de uma } \\
\text { universidade pública. }\end{array}$ \\
\hline 9. & Ávila (2011) & $A$ & $\begin{array}{c}\text { As transformações do trabalho docente } \\
\text { através da produção escrita da anped } \\
\text { (1996-2009). }\end{array}$ \\
\hline
\end{tabular}

10. Ax Wilhelm \& Zanelli (2013)

11. Bachion et al. (2005)

12. Bernardo (2014)

13. Bianchetti \& Machado (2007)

14. Borsoi (2012)

15. Borsoi \& Pereira (2013)

16. Braga Júnior (2013)
A Características das situações estressantes em gestores universitários no contexto do trabalho

A Vulnerabilidade ao estresse entre professores de uma universidade pública.

A Produtivismo e precariedade subjetiva na universidade pública: o desgaste mental dos docentes.

A "Reféns da produtividade" - sobre produção do conhecimento, saúde dos pesquisadores e intensificação do trabalho na pós-graduação.

A Trabalho e produtivismo: saúde e modo de vida de docentes de instituições públicas de Ensino Superior

A Professores do ensino público superior: produtividades, produtivismo e adoecimento

D Saúde vocal e docência no ensino superior 
Tabela 2. Continuação.

$\begin{array}{cccc}\text { No } & \text { Autor(a)/Ano } & \text { Tipo } & \text { Título } \\ \text { 17. } & \text { Campos (2011) } & \text { D } & \begin{array}{c}\text { Trabalho docente e saúde: tensões da } \\ \text { educação superior }\end{array}\end{array}$

18. Caran et al.(2011)

A Riscos ocupacionais psicossociais e sua repercussão na saúde de docentes universitários

19. Caran et al. (2010)

A Assédio moral entre docentes de instituição pública de ensino superior do Brasil.

20. Cassandre (2011)

A A saúde de docentes de pós-graduação em universidades públicas: os danos causados pelas imposições do processo avaliativo

21. Christophoro \&

A

Stress: condições de trabalho em docentes universitários

22. Costa et al. (2005)

Percepções sobre o estresse entre professores universitários

23. Costa Júnior (2011)

Política de avaliação da pós-graduação e suas consequências $n$ o trabalho dos professores-pesquisadores

24. Cupertino (2012)

D Prazer e sofrimento na prática docente no ensino superior: estudo de caso em uma IFES mineira

25. Dini (2013)

D Condições de saúde, trabalho e hábitos de vida de trabalhadores de um campus universitário

26. Fernandes et al.

A (2009)

Estilo de vida de professores universitários: uma estratégia para a promoção da saúde do trabalhador

27. Ferreira (2011)

D Satisfação no trabalho de docentes de uma instituição pública de ensino superior: reflexos na qualidade de vida

28. Filho \& Naujorks A O professor de Medicina da UFSM no (2005) contexto do mal-estar docente

29. Forattini \& Lucena A Adoecimento e sofrimento docente na (2015) perspectiva da precarização do trabalho 
Tabela 2. Continuação.

$\begin{array}{cccc}\text { No } & \text { Autor(a)/Ano } & \text { Tipo } & \text { Título } \\ \text { 30. Freitas (2013) } & \text { D } & \begin{array}{c}\text { As relações existentes entre as atividades } \\ \text { intensivas em conhecimento e o } \\ \text { absenteísmo involuntário de professores } \\ \text { universitários: o caso da Universidade } \\ \\ \end{array} \quad \text { Federal de Santa Catarina }\end{array}$

31. Freitas (2015)

32. Gradella Júnior (2010)

33. Gueiros (2005)

34. Hashizume (2010)

35. Heijmans (2005)

36. Lago et al. (2015)

$37 . \quad$ Léda (2006)

38. Léda (2007)

A

39. Lemos (2005)

40. Lemos (2011)

41. Liduário (2013)

A
D Adoecimento relacionado ao trabalho de docentes universitários da área da saúde

Sofrimento psíquico e trabalho intelectual

Estresse ocupacional de professores: seus indicadores, suas fontes e as estratégias utilizadas para combatê-lo um estudo de caso na Universidade Federal de Pernambuco

Saúde e afeto na docência: a busca incessante pela vida - estudo com professores de uma universidade pública

A Universidade, produção do conhecimento e avaliação.

A Percepção do trabalho docente em uma universidade da região norte do Brasil

A Trabalho docente no ensino superior sob o contexto das relações sociais capitalistas.

Universidade nova/plano de reestruturação e expansão das universidades federais: mais uma dose da reforma universitária?

T Cargas psíquicas no trabalho e processos de saúde em professores universitários

A Trabalho docente nas universidades federais: tensões e contradições

A mercantilização e privatização do ensino superior e seus rebatimentos sobre a saúde do docente 
Tabela 2. Continuação.

\begin{tabular}{|c|c|c|}
\hline Autor(a)/Ano & Tipo & Título \\
\hline 42. Lima \& Althus (2016) & A & $\begin{array}{l}\text { Formação docente continuada, } \\
\text { desenvolvimento de práticas } \\
\text { pedagógicas em sala de aula e } \\
\text { promoção da saúde do professor: } \\
\text { relações necessárias }\end{array}$ \\
\hline
\end{tabular}

43. Lima \& Lima-Filho (2009)

44. Magalhães (2014)

45. Mattos (2013)

46. Meguins (2015)

47. Mendes et al. (2007)

48. Mota et al. (2014)

49. Mota Júnior (2011)

50. Mulato (2008)

51. Nascimento (2012)

52. Nunes et al. (2014)

53. Oliveira \& Cardoso (2011)
A Condições de trabalho e saúde do/a professor/a universitário/a

A Proletarização e mal-estar docente nas universidades públicas: uma perspectiva crítica

A A greve das universidades federais no Brasil em 2012

A O apelo ideológico ao fetichismo acadêmico: a moeda de troca das políticas neoliberais para a educação superior

A Da arte ao ofício: vivências de sofrimento e significado do trabalho de professor universitário

A Sintomas osteomusculares de servidores de uma universidade pública brasileira: um estudo ergonômico

D Os impactos do Sistema CAPES de avaliação sobre o trabalho docente na pós-graduação: o caso da UFPA

D O docente universitário em Enfermagem e a Síndrome de Burnout: uma questão de educação para a saúde

A expansão da educação superior e o trabalho docente - um estudo sobre o plano nacional de formação de professores da educação básica (PARFOR) na UFPA

A Subjective well-beingand time use of brazilian PhD professors

A Stress e trabalho docente na área de saúde 
Tabela 2. Continuação.

\begin{tabular}{|c|c|c|c|}
\hline $\mathbf{N}^{\circ}$ & Autor(a)/Ano & Tipo & Título \\
\hline 54. & $\begin{array}{l}\text { Paiva \& Saraiva } \\
\text { (2005) }\end{array}$ & A & $\begin{array}{l}\text { Estresse ocupacional de docentes do } \\
\text { ensino superior }\end{array}$ \\
\hline 55. & Pizzio \& Klein (2015) & A & $\begin{array}{c}\text { Qualidade de vida no trabalho e } \\
\text { adoecimento no cotidiano de docentes } \\
\text { do Ensino Superior }\end{array}$ \\
\hline 56. & Queiroz (2014) & $\mathrm{T}$ & $\begin{array}{l}\text { O mal-estar e o bem-estar na docência } \\
\text { superior: a dialética entre resiliência e } \\
\text { contestação }\end{array}$ \\
\hline 57. & Resende (2005) & $\mathrm{T}$ & $\begin{array}{c}\text { Formação e autonomia do professor } \\
\text { universitário: um estudo na Universidade } \\
\text { Federal de Goiás }\end{array}$ \\
\hline
\end{tabular}

58. Rocha \& Léda (2015)

A Reflexões sobre o magistério superior no instituto federal de educação, ciência e tecnologia

59. Rodrigues (2012)

A O REUNI na UFF: o impacto no trabalho docente

60. Rohde (2012)

D Qualidade de vida no trabalho sob a perspectiva de professores de ensino superior

61. Santos (2012)

D Condições de trabalho e transtornos mentais comuns em professores universitários

62. Santos (2013)

D Bem estar e condições de trabalho de professores do centro de ciências da saúde da Universidade Federal de Pernambuco

63. Scherer (2004)

D Estresse e estratégias de enfrentamento em professores universitários

64. Seabra \& Dutra (2015)

A Intensificação do trabalho e percepção da saúde em docentes de uma Universidade pública Brasileira

65. Servilha et al. (2010) A Riscos ocupacionais na legislação trabalhista brasileira: destaque para aqueles relativos à saúde e à voz do professor 
Tabela 2. Continuação.

\begin{tabular}{|c|c|c|c|}
\hline $\mathbf{N}^{\circ}$ & Autor(a)/Ano & Tipo & Título \\
\hline 66. & Silva (2015) & A & $\begin{array}{l}\text { Adoecimento e sofrimento de } \\
\text { professores universitários: dimensões } \\
\text { afetivas e ético-políticas }\end{array}$ \\
\hline 67. & Silva (2006) & $\mathrm{T}$ & $\begin{array}{l}\text { Características do estilo de vida e da } \\
\text { qualidade de vida de professores do } \\
\text { ensino superior público em educação } \\
\text { física. }\end{array}$ \\
\hline 68. & Silva e Souza (2004) & $A$ & $\begin{array}{l}\text { Fatores de risco para hipertensão arterial } \\
\text { sistêmica versus estilo de vida docente }\end{array}$ \\
\hline 69. & $\begin{array}{l}\text { Silva Júnior et al. } \\
\qquad(2013)\end{array}$ & $A$ & $\begin{array}{l}\text { Mundialização e o trabalho do ser social } \\
\text { professor pesquisador }\end{array}$ \\
\hline 70. & Soares et al. (2011) & $A$ & $\begin{array}{c}\text { Fatores facilitadores e impeditivos no } \\
\text { cuidar de si para docentes de } \\
\text { enfermagem. }\end{array}$ \\
\hline 71. & Sousa (2013) & $\mathrm{D}$ & $\begin{array}{l}\text { O perfil do adoecimento docente na } \\
\text { Universidade de Brasília de } 2006 \text { a } 2011\end{array}$ \\
\hline 72. & Stehling et al. (2015) & $A$ & $\begin{array}{c}\text { Fatores de risco para a ocorrência de } \\
\text { acidentes em laboratórios de ensino e } \\
\text { pesquisa em uma universidade brasileira } \\
\text { (2012) }\end{array}$ \\
\hline 73. & Tavares (2010) & $\mathrm{D}$ & $\begin{array}{l}\text { Distúrbios psíquicos menores em } \\
\text { enfermeiros docentes }\end{array}$ \\
\hline 74. & Tomé et al. (2013) & $A$ & $\begin{array}{c}\text { Health problems awareness during travel } \\
\text { among faculty members of a large } \\
\text { university in Latin America. Preliminary } \\
\text { report }\end{array}$ \\
\hline 75. & Vilela et al. (2013) & $A$ & $\begin{array}{c}\text { Vivências de prazer-sofrimento no } \\
\text { trabalho do professor universitário: } \\
\text { estudo de caso em uma instituição } \\
\text { pública }\end{array}$ \\
\hline 76. & Xavier et a. (2010) & $A$ & $\begin{array}{c}\text { Fatores de risco cardiovascular entre } \\
\text { docentes de uma universidade pública } \\
\text { de Minas Gerais }\end{array}$ \\
\hline
\end{tabular}

Apesar de os textos transitarem e dialogarem com vários temas relacionados ao trabalho docente observou-se uma aproximação de objetivos nos estudos. $\mathrm{Na}$ categorização das pesquisas, adotou-se o critério de dar destaque ao assunto que mais sobressaiu em cada publicação. Grande parte das publicações 
analisadas se ocupou das temáticas da Saúde e do Trabalho. Pode-se categorizar nas publicações os seguintes núcleos de interesses:

Núcleo 1): Relacionados ao trabalho docente: a) 36 (47\%) abordaram questões gerais de saúde, não focando apenas em questões de ordem psicológica (textos: $1 ; 4 ; 6 ; 7 ; 8 ; 12 ; 16 ; 17 ; 18 ; 19 ; 2 ; 20 ; 24 ; 25 ; 28 ; 30 ; 31 ; 32 ; 34 ; 40 ; 41 ; 43 ; 44 ; 47 ; 48$; 50; 52; 56; 65; 70; 71; 72; 74; 75; 76), b) 10 (13\%) apresentaram discussões sobre a categoria trabalho (textos: 9; 14; 15; 36; 37; 39; 45; 46; 64; 69), c) 10 (13\%) focaram nos fenômenos de desgaste, estresse, e transtornos mentais (textos: 10; $11 ; 21 ; 22 ; 33 ; 53 ; 54 ; 61 ; 63 ; 66 ; 73)$, e, d) 7 textos $(9,2 \%)$ apresentaram como base de discussão a noção de qualidade de vida $(26 ; 27 ; 55 ; 60 ; 62 ; 67 ; 68)$.

Núcleo 2): Políticas - 13 (17\%) pesquisas se dedicaram a analisar as relações das Políticas Educacionais, Avaliação e Formação Docente, bem como os impactos do Programa Reestruturação e Expansão das Universidades Federais Brasileiras (REUNI) e reflexos na saúde docentes (textos: $3 ; 5 ; 13 ; 23 ; 29 ; 35 ; 38 ; 42 ; 49 ; 51 ; 57$; $58 ; 59)$.

Sobre as situações de trabalho, levantou-se nas publicações relatos de condições objetivas, subjetivas ou da organização do trabalho que os autores trouxeram para a discussão como possíveis influenciadores na saúde docente, um mesmo estudo pode ter descrito mais de uma situação. Encontrou-se em 47 (61\%) publicações direcionamentos sobre circunstâncias avaliadas como provocadoras de desgaste em seus trabalhadores; 38 (50\%) descreveram que o trabalho nas universidades está intensificado; 35 (46\%) destacaram a sobrecarga de trabalho; $31,5 \%$ (24) relataram a precarização do trabalho docente (relações contratuais frágeis, condições de trabalho precárias, etc.); 20 (26\%) apontaram o aumento do produtivismo acadêmico (excessiva exigência por publicações como forma de avaliação); outras 20 (26\%) declararam incremento da competição entre pares (gerada especialmente pelo produtivismo); 10 (13\%) deram ênfase ao processo avaliativo como gerador de sofrimento; 10 (13\%) publicações enfatizaram as mudanças ocorridas nos anos 1990 (reestruturação produtiva) como grandes influenciadoras das condições de trabalho atuais; 8 (10\%) relacionam o modo como ocorreu a expansão/reestruturação das instituições federais de ensino com a precarização e o adoecimento docente encontrado na realidade, da mesma maneira, 7 (9\%) discutiram que o docente do ensino superior tem se transformado em "professor/empreendedor" por se sentir impelido a angariar recursos financeiros externos para o desenvolvimento de pesquisa, e, por fim, um estudo comparou o profissional docente ao trabalhador proletário.

Seguindo os objetivos propostos no presente estudo, com base no conceito de "cargas de trabalho", trazida por Lemos (2005) fundamentado em Laurell e Noriega (1989), como um aglomerado de esforços criados com a função de atingir as exigências das tarefas que envolvem custos físicos, cognitivos e psicoafetivos (emocionais), procedeu-se a um levantamento, na literatura 
analisada, de descrições de cargas de trabalho na atividade docente que podem ser vistas na Tabela 3.

Tabela 3.

Cargas de trabalho identificadas nos estudos

\begin{tabular}{l|c|c} 
Cargas registradas & No de & Frequência \\
Publicações & em \% \\
que registram &
\end{tabular}

\section{Externas: físicas/químicas/biológicas/mecânicas}

Estado de conservação e/ou ausência de estrutura, materiais e equipamentos

Temperatura/ruído/umidade/ ventilação insatisfatórios

Ergonomia/desconforto/mobiliário inadequado

Exposição a riscos de contaminação

Sujeira/Poeira

Ficar em pé

\section{Internas: fisiológicas/psicológicas}

Pressões/metas por publicação/produtividade

Excesso de atividades de trabalho

Relacionamentos interpessoais

Competição

Insatisfação salarial

Carga horária excessiva

Ritmo acelerado/estressante

Avaliação (progressão de carreira e de cursos de graduação e programas de pós-graduação)

Violência

Insatisfação com o trabalho

Atividades administrativas

Trabalhar com falta de recursos

Ambiguidade de papéis

Além de apontar as cargas, as pesquisas sugerem que, em decorrência do tipo de organização laboral, os docentes podem desenvolver doenças, transtornos e sintomas que nem sempre são diagnosticados como resultado das situações de trabalho. A Tabela 4 expressa o levantamento das principais descrições em 
termos de desgaste docente presentes nas publicações, igualmente, um mesmo estudo pode ter registrado mais de uma condição:

\section{Tabela 4.}

\section{Desgastes registrados nos estudos analisados}

Adoecimentos - Sintomas - Sofrimento -
Transtornos

$\mathrm{N}^{\circ}$ de publicações que registram os fenômenos

Desgaste mental; estresse
Frequência em $\%$

51,3

Dores osteomusculares/

musculoesqueléticas

25,0

Depressão

16

21,1

Problemas relativos ao sono; bruxismo

Burnout

Ansiedade

Cansaço; exaustão

Problemas com a voz

Dor (cabeça/corpo)

Transtornos mentais comuns (TMC)

Nervosismo; irritação; mau-humor

Hipo/hipertensão arterial

Uso de medicação prescrita e

automedicação

Problemas no trato digestivo

Problemas cardiovasculares;

taquicardia; infarto

Problemas de concentração em memória

Alergias

Mal-estar

Diabetes

Labirintite

Frustração por falta de reconhecimento 
Tabela 4. Continuação.

\begin{tabular}{|c|c|c|}
\hline $\begin{array}{c}\text { Adoecimentos - Sintomas - Sofrimento - } \\
\text { Transtornos }\end{array}$ & $\begin{array}{l}N^{\circ} \text { de publicações } \\
\text { que registram os } \\
\text { fenômenos }\end{array}$ & $\begin{array}{l}\text { Frequência } \\
\quad \text { em \% }\end{array}$ \\
\hline $\begin{array}{l}\text { Problemas psíquicos e somáticos; } \\
\text { sofrimento mental }\end{array}$ & 5 & 6,6 \\
\hline Sedentarismo, sobrepeso e obesidade & 4 & 5,3 \\
\hline Absenteísmo e presenteísmo & 3 & 3,9 \\
\hline $\begin{array}{l}\text { Distúrbios hormonais; endócrinos; } \\
\text { metabólicos }\end{array}$ & 2 & 2,6 \\
\hline Acidente vascular cerebral (AVC) & 2 & 2,6 \\
\hline $\begin{array}{l}\text { Dificuldade de relacionar-se; } \\
\text { isolamento }\end{array}$ & 2 & 2,6 \\
\hline Câncer & 2 & 2,6 \\
\hline Tabagismo & 1 & 1,3 \\
\hline Bronquite & 1 & 1,3 \\
\hline Baixa-autoestima & 1 & 1,3 \\
\hline $\begin{array}{l}\text { Infecção urinária (por não beber água } \\
\text { pela falta de tempo) }\end{array}$ & 1 & 1,3 \\
\hline Acidente de trabalho & 1 & 1,3 \\
\hline Varizes & 1 & 1,3 \\
\hline
\end{tabular}

Considerando que descrições como insônia, fadiga, irritabilidade, esquecimento, dificuldade de concentração e queixas somática referem-se aos transtornos mentais menores, inclui-se várias descrições dentro do espectro das questões psíquicas, corroborando com a leitura de que o conjunto maior de problemas apresentados, quando se observa o desgaste no trabalho docente no ensino superior, é do campo do sofrimento mental. É pertinente esclarecer que, como optou-se, neste estudo, por não adentrar a discussão proposta pela psicodinâmica do trabalho, - embora muito pertinente - o termo "sofrimento mental" não foi utilizado nesta pesquisa como um descritor na busca de publicações, portanto não foram contemplados os estudos que tratam dessa abordagem específica que se dedica a analisar as relações entre prazer e sofrimento no trabalho. Sabe-se da existência de mais produções nesse campo, porém, aqui, as discussões sobre esse viés se dão pelo fato de o termo ter aparecido em algumas publicações diante das outras palavras-chave pesquisadas.

\section{DISCUSSÃO}


As publicações encontradas versam sobre as situações de trabalho e desgaste em várias dimensões, sendo o desgaste psicológico o mais evidenciado. Isso fica manifesto nas descrições de sintomas, adoecimentos, e/ou sofrimento que foram agrupados na Tabela 3, na qual o desgaste no trabalho, aparecendo muitas vezes sob o nome de estresse laboral, é citado em 39 textos, ou seja, mais de $50 \%$ das publicações. Parte das publicações se encarregou de avaliar condições estressantes, vulnerabilidade ao estresse e estratégias de enfrentamento desse fenômeno específico. Também fica visível na Tabela 2, que grande parte das cargas envolvidas no trabalho docente tem relação com questões psicológicas.

Observar estes resultados leva a recobrar Clot (2013), que afirma que, em geral, quando situação de trabalho não possibilita a produção e manutenção da saúde, a doença pode ter espaço para seu desenvolvimento e estabelecimento. Não havendo possibilidades de modificação e transformação da realidade, os sujeitos deixam de viver, e meramente 'sobrevivem' em contextos profissionais, nos quais, muitas vezes não se reconhecem.

Outrossim, é preciso lembrar que no adoecimento relacionado ao trabalho existe grande resistência para reconhecer o nexo causal entre atividade de trabalho e produção de doença. Não raro, os desgastes que evoluem para doenças têm diagnóstico ligado a outras origens que quase nunca contemplam as questões sociais, dentre elas, o trabalho. Quando o fazem, os diagnósticos biomédicos, não atentos, tendem a orientar para a compreensão de um sujeito que adoece por não ter sido hábil em se adaptar às condições laborais 'normais'.

Por isso, é crucial pensar nos processos de adaptação, não só como processos fisiológicos normais programados ou esperados, mas como as situações às quais os trabalhadores são levados a suportar cargas de trabalho, arriscando-se, até que algum adoecimento se estabeleça. Os processos de adaptação (Laurell \& Noriega, 1989; Pina \& Stotz, 2014) significam, para além da sobrevivência, possibilidades de destruir-se pela exposição constante às condições que parecem estar sob controle e/ou que seriam adaptáveis.

Tal adaptação pode gerar sobrevivência em condições desfavoráveis ou destruição pela longa tentativa de se restabelecer diante de contextos precários. O fato de o ambiente incidir nos corpos não implica que a vivência seja individual. Antes de tudo, é uma experiência social, configurada em "modos de andar de vida" (forma de viver experiências) e criações coletivas (Laurell \& Noriega, 1989; Pina \& Stotz, 2014). Assim, percebe-se que quando o sujeito se vê desgastado em decorrência de seu trabalho, em especial no quesito psíquico, nem sempre as instâncias que o adoeceram são eleitas como causas. Em geral dá-se muita importância à influência da personalidade, fatores genéticos e até mesmo às questões da vida familiar como aspectos causadores da desordem, evitando e ocultando o verdadeiro impacto do trabalho no fenômeno do adoecimento/sofrimento (Seligmann-Silva, 1988; 2011). 
Ora, sendo a articulação com o meio algo do plano individual que se constrói por meio do coletivo, não se pode relegar os resultados das vivências apenas ao indivíduo. As formas coletivas servem ao estabelecimento do nexo biopsíquico. A existência de um movimento de individualização do sofrimento tem como foco negar condições que precisam ser modificadas, pois experiências individuais isoladas impedem a justificativa de que as consequências de um determinado trabalho são coletivas (Laurell \& Noriega, 1989; Neves, 2013;).

As cargas internas registradas pelas publicações, por exemplo, demonstram que os docentes 'precisam', sobretudo, trabalhar mais (invasão do trabalho na vida privada/usurpação do lazer) para conseguir atingir as exigências estabelecidas (pressões/metas por publicação/produtividade), que orientam o desenvolvimento da carreira docente (avaliação) e o recebimento de verbas e/ou custeio para manutenção da universidade.

Essa realidade remete ao conceito de mais-valia trazido por Marx (1996), de acordo com o qual se explica o acúmulo e 'sucesso' do sistema capitalista: a exploração de seus trabalhadores (Loyola, 2009). Estando o sistema educacional orientado pela mesma perspectiva, é possível observar as vivências hostis relatadas nos estudos, que apontam dificuldades nos relacionamentos interpessoais (competição) e na relação com as próprias situações de trabalho, que, se de um lado são permeadas pelo prazer de compor este espaço laboral, de outro, chocam-se com a insatisfação salarial, insatisfação com o trabalho, altas demandas psicológicas/baixo nível de controle, ambiguidade de papéis, falta de recursos, dificuldades com atividades administrativas, chegando ao ponto do trabalho ser avaliado como "emocionalmente pesado".

Acerca da sobrecarga e intensificação do trabalho, amplamente registradas nos estudos, pode-se pensar que circunstâncias nas quais os professores executam a sua atividade de trabalho, regularmente exigem dispêndio de forças físicas, cognitivas e afetivas para cumprir os objetivos próprios da educação, requerendo, muitas vezes, sobre-esforço ou hiper-solicitação psicofisiológica, desse modo, o tempo livre funcionaria como uma forma de se recuperar. Acontece que, conforme explicam Gasparini, Barreto e Assunção (2015) com o ritmo de trabalho intensificado, não há tempo livre. Logo, quando não existe o espaço temporal para a recuperação, a consequência é o provável desenvolvimento dos sintomas clínicos, com o potencial de culminarem em transtornos mentais.

Diante dessa realidade, quando existe a manifestação de sintomas que sejam decorrentes das cargas de trabalho vivenciadas, é comum que não haja a percepção desta relação, afirmando Araújo e Martins (2009) que a saúde docente é uma questão não inclusa nas preocupações do setor da educação, pela própria gestão e, claro, por parte de muitos docentes, já que não são estimulados a considerar tais relações. É 'naturalizado' que esse profissional cuida e ensina o outro, mas não se fomenta o olhar para si mesmo e sua saúde. Sintomas de adoecimento são negados ou minimizados, exigindo grande severidade para o 
reconhecimento de sua existência e, via de regra, o processo de adoecimento é vivenciado como algo individual.

Por conseguinte, o sujeito, sem conseguir evitar a doença, já que foge ao seu controle, tende a domesticar, conter, e aprende a viver com tal adoecimento/sofrimento. Isso se caracteriza como uma problemática, provocando em si mesmo possibilidade de desgaste mental, por vezes levando ao presenteísmo, conhecido como um fenômeno que envolve a prática de não revelar os sintomas ou adoecimentos em decorrência do medo de perder o emprego, caso necessite de afastamento (Franco, Druck, \& Seligmann-Silva, 2010).

Antunes e Praun (2015), ao dissertarem sobre a sociedade dos adoecimentos no trabalho, apontam que a própria origem de tais processos, entre outros fatores, encontra na individualização do trabalho e na ruptura do tecido de solidariedade um contexto para o enfraquecimento das possibilidades de saúde, já que fragmentação das relações de apoio e solidariedade entre os pares leva ao afastamento das estratégias coletivas de defesa que antes eram usadas pelos trabalhadores de forma adaptativa. Os autores afirmam que esse fenômeno se constitui como alicerce do aumento da afetação ao bem-estar psicológico, incluindo uma de suas manifestações mais severas, como o suicídio no ambiente trabalho, ou relacionado a ele.

Isso posto, é importante reafirmar que os sentimentos de coletividade e de pertencimento são positivos para a saúde do trabalhador, que são favoráveis à capacidade de mobilização coletiva, e as entidades sindicais dever estar politicamente fortalecidas e podem contribuir no apoio aos trabalhadores diante do sofrimento vivenciado dentro e fora do local de trabalho. Apesar disso, a lógica de funcionamento contemporânea afeta a mobilização coletiva no trabalho, sentindo igualmente o efeito direto a individualização e o isolamento dos sujeitos. É provavelmente por este motivo, em que pese os sindicatos atuais tenham ser organizado por melhoria nas condições salariais e objetivas de trabalho, pouco se discute sobre a saúde dos trabalhadores, sendo mais escassas ainda ou pouco reconhecidas as discussões sobre o sofrimento psicológico nesse espaço (Antunes \& Praun, 2015).

$\mathrm{Na}$ direção do não reconhecimento e individualização, o isolamento dos trabalhadores e trabalhadoras em contextos laborais que não permitem a apropriação e configurações de coletivos profissionais foi ilustrado nos quase $25 \%$ das publicações analisadas que discutem dificuldades na ordem dos relacionamentos interpessoais e vivência de competição entre pares. Clot (2002) explica esse fenômeno por meio do conceito de suspenção da história do gênero profissional, no qual "(...) a produção coletiva das expectativas genéricas do ofício é posta em sofrimento. Cada um individualmente se encontra então confrontado às más surpresas de uma organização do trabalho que deixa 'sem voz' face ao real (Clot, 2002, p. 04)". 
É, portanto, importante destacar que a saúde se degrada no ambiente do trabalho quando o coletivo profissional se restringe a união de pessoas sujeitas ao isolamento, no qual o trabalho coletivo não consegue se apropriar do coletivo de trabalho. Tal coletivo de trabalho, segundo a abordagem da clínica da atividade possui uma função psicológica capaz de conservar ou restabelecer a vitalidade dialógica do social, constituindo-se em um importante instrumento para uma ação transformadora (Clot, 2010).

Por sua vez, a ação transformadora, pode ser construída com diferentes agentes, as publicações analisadas trazem sugestões para transformar a realidade, as recomendações encontradas permitem conectar evidências e necessidades relacionadas ao campo da saúde/adoecimento no trabalho docente: 1) urgência de novos estudos na área com divulgação acadêmica dos resultados que demonstrem as relações entre as situações de trabalho docente e o adoecimento; 2) necessidade de envolvimento da gestão universitária e dos sindicatos dos trabalhadores; 3) sugestão de aplicação da norma regulamentadora 17 ergonomia (Ministério do Trabalho, 1990), à profissão docente, cujo objetivo é a adaptação das condições de trabalho em relação às necessidades psicofisiológicas dos trabalhadores com foco no conforto e segurança considerando manejo de peso, equipamentos, aspectos ambientais e a organização do trabalho; 4) elaboração de ações/programas de enfrentamento e/ou preventivas (atividade física; nutrição, fonoaudiologia, psicologia, segurança no trabalho, etc.); 5) necessidade de fortalecimento da política nacional de saúde do trabalhador; 6) necessidade de desenvolvimento de protocolos para evitar acidentes de trabalho; e, 7) reformulação da política de readaptação por motivo de doença. As recomendações citadas não esgotam as ações necessárias para modificação do cenário registrado pelos estudos, porém, certamente podem colaborar no enfrentamento das situações encontradas.

\section{CONSIDERAÇÕES FINAIS}

A integração dos apontamentos trazidos pelos estudos em torno do problema investigado permitiu observar evidências importantes sobre o processo de adoecimento docente. Gradualmente, formas de organizar o trabalho, as estruturas, as condições laborais inadequadas e determinados tipos de políticas educacionais se instalaram nas universidades públicas como fatores que precarizam o trabalho nos mais diversos sentidos, dos mais objetivos aos mais subjetivos, e essa realidade parece estar contribuindo, quando não, causando o adoecimento e/ou o sofrimento dos trabalhadores.

Merece destaque em todo esse processo, a sutileza com a qual a precarização das situações de trabalho e adoecimentos decorrentes têm sido naturalizados. Tornou-se natural responder à pressão por produtividade, produzindo. Parte das explicações concentra-se no fato de que muitas avaliações que geram progressões na carreira e financiamento de recursos para as instituições 
dependem do cumprimento de metas e das exigências impostas, não considerando, todavia, os limites humanos que escapam a tal lógica.

Não se pode deixar de observar, igualmente, que de acordo com as publicações, as cargas internas de trabalho (psicológicas e fisiológicas) mais registradas nas pesquisas analisadas possuem potencial etiológico quando consideradas as formas de acometimentos mais vivenciados (adoecimentos, sintomas, sofrimento e transtornos).

É importante esclarecer que não se trata de estabelecer leviana relação direta de causa e efeito, tampouco de vilanizar a docência, mas da necessidade de uma observação mais profunda sobre as relações entre as situações nas quais ela têm se desenvolvido e possíveis influências na vida de seus trabalhadores e trabalhadoras. Também é necessário que novos estudos sejam realizados principalmente no que concerne a possíveis formas de enfrentamento a tais condições desgastantes, já que é um fenômeno que deve ser estudado por diferentes óticas.

Ainda que não tenha composto o objetivo geral deste estudo, é preciso registrar que não obstante as formas de adoecimento e sofrimento encontradas, o prazer pelas atividades da docência também foi registrado nas publicações. Isso mostra que o trabalho desempenha importante papel de formação de subjetividade. Assim, observa-se a necessidade de apontar situações que não colaboram com uma vivência ampla, e, por que não pensar em enfrentamentos que possibilitem uma docência que seja desenvolvida como possibilidade de emancipação, de manutenção justa das necessidades da vida diária e como atividade geradora de saúde nos seus mais amplos determinantes?

\section{REFERÊNCIAS ${ }^{2}$}

*Albuquerque, A. G. (2013). Relação entre condições de trabalho e saúde vocal de professores no ensino superior (Dissertação de Mestrado). Universidade Federal de Pernambuco, Vitória de Santo Antão.

*Alves, L. A. (2007). Parâmetros vocais e percepção vocal de professores universitários (Dissertação de Mestrado). Universidade de São Paulo, Ribeirão Preto.

*Andrade, L. V. V. de. (2014). Trabalho docente e saúde ocupacional na Universidade Federal de Uberlândia. (Dissertação de Mestrado). Universidade Federal de Uberlândia, Uberlândia.

Antunes, R., \& Praun, L. (2015). A sociedade dos adoecimentos no trabalho. Revista Serviço Social \& Sociedade, (123), 407-427. doi: 10.1590/0101-6628.030

*Araújo, G. L. (2013). A nova geração de professores universitários: Profissionalização, condições de trabalho e sua relação com a produtividade científica na UFRGS (Dissertação de Mestrado). Universidade Federal do Rio Grande do Sul, Porto Alegre.

*Araújo, J. P. (2012). Afastamento do trabalho: Absenteísmo e presenteísmo em uma instituição federal de ensino superior (Dissertação de Mestrado). Universidade de Brasília, Brasília.

*Araújo, T. M. D., \& Martins, F. C. (2009). Condições de trabalho docente e saúde na Bahia: estudos epidemiológicos. Educação \& Sociedade, 3a(107), 427-449. doi: 10.1590/S010173302009000200007

*Araújo, T. M. de., Sena, I. P., Viana, M. A., \& Araújo, E. M. (2005). Mal-estar docente: avaliação de condições de trabalho e saúde em uma instituição de ensino superior. Revista Baiana de Saúde Pública, 29(1), 6-21. doi: 10.22278/2318-2660.2005.v29.n1.a108. 
*Arbex, A. P. S., Souza, K. R., \& Mendonça, A. L. O. (2013). Trabalho docente, readaptação e saúde: A experiência dos professores de uma universidade pública. Physis, 23(1), 263-284. doi: 10.1590/S0103-73312013000100015

*Ávila, S. de F. O. de. (2011, outubro). As transformações do trabalho docente através da produção escrita da Anped (1996-2009). Anais da $34^{\circ}$ Reunião Anual da Anped. Natal, RN: Associação Nacional de Pós-Graduação e Pesquisa em Educação.

*Ax Wilhelm, F., \& Zanelli, J. C. (2013). Características das situações estressantes em gestores universitários no contexto do trabalho. Estudos e Pesquisas em Psicologia, 13(2), 704-723. doi: 10.12957/epp.2013.8432

*Bachion, M. M., Abreu, L. de O., Godoy, L. F., \& Costa, E. C. (2005). Vulnerabilidade ao estresse entre professores de uma universidade pública. Revista de Enfermagem UERJ, 13(1), 32-37.

*Bernardo, M. H. (2014). Produtivismo e precariedade subjetiva na universidade pública: O desgaste mental dos docentes. Psicologia \& Sociedade, 26(n. esp.), 129-139. doi: 10.1590/S010271822014000500014.

*Bianchetti, L., \& Machado, A. M. N. (2007, outubro). "Reféns da produtividade" - Sobre produção do conhecimento, saúde dos pesquisadores e intensificação do trabalho na pósgraduação. Anais da $30^{\circ}$ Reunião Anual da Anped. Caxambu, MG: Associação Nacional de Pós-Graduação e Pesquisa em Educação.

*Borsoi, I. C. F. (2012). Trabalho e produtivismo: Saúde e modo de vida de docentes de instituições públicas de Ensino Superior. Cadernos de Psicologia Social do Trabalho, 15(1), 81-100. doi: 10.11606/issn.1981-0490.v15i1p81-100

*Borsoi, I. F., \& Pereira, C. F. S. (2013). Professores do ensino público superior: Produtividades, produtivismo e adoecimento. Universitas Psychologica, 12(4), 1211-1233.

Botelho, L. L. R., Cunha, C. C. A., \& Macedo, M. (2011). O método da revisão integrativa nos estudos organizacionais. Gestão \& Sociedade, 5(11); 121-136. doi: 10.21171/ges.v5i11.1220

*Braga Júnior, F. V. (2013). Saúde vocal e docência no ensino superior. (Dissertação de Mestrado). Universidade Federal Rural do Semi - Árido, Mossoró.

*Campos, F. J. de S. (2011). Trabalho docente e saúde: Tensões da educação superior. (Dissertação de Mestrado). Universidade Federal do Pará, Belém.

${ }^{*}$ Caran, V. C. S., Freitas, F. C. T. de., Alves, L. A., Pedrão, L. J., \& Robazzi, M. L. do C. C. (2011). Riscos ocupacionais psicossociais e sua repercussão na saúde de docentes universitários. Revista de Enfermagem UERJ, 19(2), 255-261.

*Caran, V. C. S., Secco, I. A. de O., Barbosa, D. A., \& Robazzi, M. L. C. C. (2010). Assédio moral entre docentes de instituição pública de ensino superior do Brasil. Acta Paulista de Enfermagem, 23(6), 737-744. doi: 10.1590/S0103-21002010000600004

*Cassandre, M. P. (2011). A saúde de docentes de pós-graduação em universidades públicas: Os danos causados pelas imposições do processo avaliativo. Revista Mal-Estar e Subjetividade, 11(2), 779-816.

*Christophoro, R., \& Waidman, M. A. P. (2002). Stress: Condições de trabalho em docentes universitários. Revista Ciência, Cuidado e Saúde Maringá, 1(1),171-175. doi: 10.4025/cienccuidsaude.v1i1.5692

Clot, Y. (2002). Clínica da atividade e repetição. Cliniques Méditerranéennes 66-2002.

Clot, Y. (2007). A função psicológica do trabalho (A. Sobral, Trad.). Petrópolis, RJ: Vozes.

Clot, Y. (2010). Trabalho e poder e agir (G. J. de F. Teixeira \& M. M. Z. Viana, Trad.). Belo Horizonte, MG: Fabrefactum.

Clot, Y. (2013). O ofício como operador de saúde. Cadernos de Psicologia Social do Trabalho, 16(1), 1-11. doi: 10.11606/issn.1981-0490.v16ispe1p1-11

Corrêa, M. L.; \& Pimenta, S. M. (2014). Teorias da administração e seus desdobramentos no âmbito escolar. In M. A. M. Oliveira (Ed.), Gestão educacional: Novos olhares, novas abordagens. (pp. 22-39). Petrópolis, RJ: Vozes.

*Costa Júnior, W. R. (2011, outubro). Política de avaliação da pós-graduação e suas consequências no trabalho dos professores-pesquisadores. Anais da $34^{\circ}$ Reunião Anual da Anped. Natal, RN: Associação Nacional de Pós-Graduação e Pesquisa em Educação.

${ }^{*}$ Costa, E. C., Bachion, M. M., Godoy, L. F. de., \& Abreu, L. de O. (2005). Percepções sobre o estresse entre professores universitários. RENE, 6(3), p. 39-47.

${ }^{*}$ Cupertino, V. (2012). Prazer e sofrimento na prática docente no ensino superior: Estudo de caso em uma IFES Mineira. (Dissertação de Mestrado). Faculdade Novos Horizontes, Belo Horizonte. 
*Dini, N. C. C. (2013). Condições de saúde, trabalho e hábitos de vida de trabalhadores de um campus universitário. (Dissertação de Mestrado). Universidade Estadual Paulista, Botucatu.

*Fernandes, M. H., Porto, G. G., Almeida, L. G. D., \& Rocha, V. M. da. (2009). Estilo de vida de professores universitários: Uma estratégia para a promoção da saúde do trabalhador. Revista Brasileira em Promoção da Saúde, 22(2), 94-99. doi:10.5020/18061230.2009.p94

*Ferreira, A. C. M. (2011). Satisfação no trabalho de docentes de uma instituição pública de ensino superior: Reflexos na qualidade de vida. (Dissertação de Mestrado). Universidade Federal de Goiás, Goiânia.

*Filho, O. C. de S., \& Naujorks, M. I. (2005). O professor de medicina da UFSM no contexto do malestar docente. Revista Brasileira de Educação Médica, 29(1), 34-41. doi: 10.1590/S010055022011000100009

*Forattini, C. D., \& Lucena, C. A. (2015). Adoecimento e sofrimento docente na perspectiva da precarização do trabalho. Laplage em Revista, 1(2), 32-47. doi: 10.24115/S2446622020151219p.32-47

Franco, T., Druck, G., \& Seligmann-Silva, E. (2010). As novas relações de trabalho, o desgaste mental do trabalhador e os transtornos mentais no trabalho precarizado. Revista Brasileira de Saúde Ocupacional, 35(1), 229-248. doi: 10.1590/S0303-76572010000200006

*Freitas, C. R. (2013). As relações existentes entre as atividades intensivas em conhecimento e 0 absenteísmo involuntário de professores universitários: O caso da Universidade Federal de Santa Catarina. (Dissertação de Mestrado). Universidade Federal de Santa Catarina, Florianópolis.

*Freitas, N. Q. (2015). Adoecimento relacionado ao trabalho de docentes universitários da área da saúde. (Dissertação de Mestrado). Universidade Federal de Santa Maria, Santa Maria.

Gasparini, S. M, Barreto, S. M., \& Assunção, A. A. (2005). O professor, as condições de trabalho e os efeitos sobre sua saúde. Educação \& Pesquisa, 31(2), 189-199. doi: 10.1590/S151797022005000200003

*Gradella Júnior, O. (2010). Sofrimento psíquico e trabalho intelectual. Cadernos de Psicologia Social do Trabalho, 13(1), 133-148. doi: 10.11606/issn.1981-0490.v13i1p133-148

*Gueiros, M. G. (2005). Estresse ocupacional de professores: Seus indicadores, suas fontes e as estratégias utilizadas para combatê-lo um estudo de caso na Universidade Federal de Pernambuco. (Dissertação de Mestrado). Universidade Federal de Pernambuco, Recife.

*Hashizume, C. M. (2010). Saúde e afeto na docência: A busca incessante pela vida - estudo com professores de uma universidade pública. (Tese de Doutorado). Universidade de São Paulo, São Paulo.

*Heijmans, R. D. (2005). Universidade, produção do conhecimento e avaliação. Educação Unisinos, 9(3), 205-215.

*Lago, R. R., Cunha, B. S., \& Borges, M. F. de S. O. (2015). Percepção do trabalho docente em uma universidade da região norte do Brasil. Trabalho, Educação e Saúde, 13(2), 429-450. doi: 10.1590/1981-7746-sip00049

Laurell, A. C., \& Noriega, M. (1989). Processo de produção de saúde. Trabalho e desgaste operário (A. Cohen, A. Pitta-Hoisel, A. I. Paraguay, \& L. H. Barbosa, Trads.). São Paulo, SP: Editora Hucitec.

*Léda, D. B. (2006, outubro). Trabalho docente no ensino superior sob o contexto das relações sociais capitalistas. Anais da $29^{\circ}$ Reunião Anual da Anped. Caxambu, MG: Associação Nacional de Pós-Graduação e Pesquisa em Educação.

*Léda, D. B. (2007, outubro). Universidade nova/plano de reestruturação e expansão das universidades federais: Mais uma dose da reforma universitária? Anais da $30^{\circ}$ Reunião Anual da Anped. Caxambu, MG: Associação Nacional de Pós-Graduação e Pesquisa em Educação.

Presidência da República. Casa Civil. (1996). Lei no 9.394, de 20 de dezembro de 1996. Estabelece as diretrizes e bases da educação nacional. Brasília, DF.

*Lemos, D. (2011). Trabalho docente nas universidades federais: Tensões e contradições. Caderno CRH, 24(n. esp. 1), 103-118. doi: 10.1590/\$0103-49792011000400008

*Lemos, J. C. (2005). Cargas psíquicas no trabalho e processos de saúde em professores universitários. (Tese de Doutorado). Universidade Federal de Santa Catarina, Florianópolis.

*Liduário, E. de A. (2013). A mercantilização e privatização do ensino superior e seus rebatimentos sobre a saúde do docente. (Dissertação de Mestrado) Universidade Estadual do Rio de Janeiro, Rio de Janeiro. 
*Lima, A., Althaus, D. (2016). Formação docente continuada, desenvolvimento de práticas pedagógicas em sala de aula e promoção da saúde do professor: Relações necessárias. Revista Brasileira de Estudos Pedagógicos, 97(245), 97-116. doi: 10.1590/S2176-6681/366113867

*Lima, M. de F. E. M., \& Lima-Filho, D. de O. (2009). Condições de trabalho e saúde do/a professor/a universitário/a. Ciências \& Cognição, 14(3), 062-082.

Loyola, P. R. G. (2009). Valor e mais-valia: examinando a atualidade do pensamento econômico de Marx. Argumentos, 1(2), 130-138.

*Magalhães, S. M. O. (2014). Proletarização e mal-estar docente nas universidades públicas: Uma perspectiva crítica. EccoS Revista Científica, 35, 211-226.

Marx, K. (1996). Processo de trabalho e processo de valorização. In K. Marx, O capital: Crítica da economia política (R. Enderle, Trad., pp. 255-275). São Paulo, SP: Nova Cultural.

*Mattos, M. B. (2013). Uma greve, várias lições. A greve das universidades federais no Brasil em 2012. Revista Iberoamericana de Educación Superior, 4(10), 135-142.

*Meguins, R. da C. (2015, outubro). O apelo ideológico ao fetichismo acadêmico: A moeda de troca das políticas neoliberais para a educação superior. Anais da $37^{a}$ Reunião Nacional da Anped. Florianópolis, SC: Associação Nacional de Pós-Graduação e Pesquisa em Educação.

*Mendes, L., Chaves, C. J. A., Santos, M. C. dos., \& Mello Neto, G. A. R. (2007). Da arte ao ofício: Vivências de sofrimento e significado do trabalho de professor universitário. Revista Malestar e Subjetividade, 7(2), 527-556.

*Mota Júnior, W. P. da. (2011). Os impactos do sistema capes de avaliação sobre o trabalho docente na pós-graduação: $O$ caso da UFPA. (Dissertação de Mestrado). Universidade Federal do Pará, Belém.

*Mota, I. L., Quadros Júnior, M. C., Munaro, H. L. R., \& Vilela, A. B. A. (2014). Sintomas osteomusculares de servidores de uma universidade pública brasileira: Um estudo ergonômico. Revista Brasileira de Promoção Saúde, 27(3), 341-348. doi: 10.5020/18061230.2014.p341

*Mulato, S. C. (2008). O docente universitário em enfermagem e a síndrome de burnout: Uma questão de educação para a saúde. (Dissertação de Mestrado). Universidade de São Paulo, Ribeirão Preto.

*Nascimento, D. de S. (2012). A expansão da educação superior e o trabalho docente - Um estudo sobre o plano nacional de formação de professores da educação básica (PARFOR) na UFPA. (Dissertação de Mestrado). Universidade Federal do Pará, Belém.

Neves, I. R. (2013). Políticas de saúde do trabalhador para o município de Corumbá: Práticas possíveis? (Tese de Doutorado). Pontifícia Universidade Católica de São Paulo, São Paulo.

Ministério do Trabalho. (1990). Norma Regulamentadora 17 - Ergonomia. Brasília, DF.

*Nunes, M. F. O., Hutz, C. S., Pires, J. G., \& Oliveira, C. M. (2014). Subjective well-beingand time use of brazilian PhD professors. Paidéia (Ribeirão Preto), 24(59), 387-387. doi: 10.1590/198243272459201412

*Oliveira, M. das G. M., \& Cardoso, C. L. (2011). Stress e trabalho docente na área de saúde. Estudos de Psicologia (Campinas), 28(2), 135-141. doi: 10.1590/S0103-166X2011000200001

*Paiva, K. C. M., \& Saraiva, L. A. S. (2005). Estresse ocupacional de docentes do ensino superior. Revista de Administração - RAUSP, 4O(2), 145-158.

Paparelli, R. (2010). Saúde mental relacionada ao trabalho: O caso de educadores da rede pública de ensino paulista. In E. Lourenço, V. Navarro, \& R. S. Sant'ana (Ed.) Avesso do trabalho II: Trabalho, precarização e saúde do trabalhador (pp. 317-342). São Paulo, SP: Expressão Popular.

Pina, J. A., \& Stotz, E. N. (2014). Intensificação do trabalho e saúde do trabalhador: uma abordagem teórica. Revista Brasileira de Saúde Ocupacional. 39(130), 150-160. doi: 10.1590/03037657000074913

*Pizzio, A., \& Klein, K. (2015). Qualidade de vida no trabalho e adoecimento no cotidiano de docentes do Ensino Superior. Educação e Sociedade, 36(131), 493-513. doi: 10.1590/ES0101-73302015124201

*Queiroz, V. da R. de F. (2014). O mal-estar e o bem-estar na docência superior: $A$ dialética entre resiliência e contestação (Tese de Doutorado). Universidade Federal de Goiás, Goiânia.

*Resende, M. do R. S. (2005). Formação e autonomia do professor universitário: Um estudo na Universidade Federal de Goiás. (Tese de Doutorado). Pontifícia Universidade Católica de São Paulo, São Paulo. 
*Rocha, L. de F. S., \& Léda, D. B. (2015, outubro). Reflexões sobre o magistério superior no instituto federal de educação, ciência e tecnologia. Anais da $37^{\circ}$ Reunião Anual da Anped. Florianópolis, SC: Associação Nacional de Pós-Graduação e Pesquisa em Educação.

*Rodrigues, V. de S. (2012, outubro). O REUNI na UFF: O impacto no trabalho docente. Anais da $35^{\circ}$ Reunião Anual da Anped. Porto de Galinhas, PE: Associação Nacional de Pós-Graduação e Pesquisa em Educação.

*Rohde, C. L. C. (2012). Qualidade de vida no trabalho sob a perspectiva de professores de ensino superior. (Dissertação de Mestrado). Universidade Federal de Santa Maria, Santa Maria.

*Santos, E. J. V. (2012). Condições de trabalho e transtornos mentais comuns em professores universitarios. (Dissertação de Mestrado). Universidade Federal de Pernambuco, Recife.

*Santos, G. B. (2013). Bem estar e condições de trabalho de professores do centro de ciências da Saúde da Universidade Federal de Pernambuco. (Dissertação de Mestrado). Universidade Federal de Pernambuco, Recife.

*Scherer, C. G. (2004). Estresse e estratégias de enfrentamento em professores universitarios. (Dissertação de Mestrado). Universidade Federal de Santa Catarina, Florianópolis.

*Seabra, M. M. A., \& Dutra, F. C. M. S. (2015). Intensificação do trabalho e percepção da saúde em docentes de uma universidade pública Brasileira. Ciencia y Trabajo, 17(54), 212-218. doi: 10.4067/S0718-24492015000300010.

Seligmann-Silva, E. (1988). Os vínculos entre condições de trabalho e saúde mental. Psicologia, Ciência \& Profissão, 8(2), 13-17. doi: 10.1590/S1414-98931988000200006

Seligmann-Silva, E. (2011). Trabalho e desgaste mental: O direito de ser dono de si mesmo. São Paulo, SP: Cortez.

*Servilha, E. A. M., Leal, R. de O. F., \& Hidaka, M. T. U. (2010). Riscos ocupacionais na legislação trabalhista brasileira: Destaque para aqueles relativos à saúde e à voz do professor. Revista Sociedade Brasileira de Fonoaudiologia, 15(4), 505-513. doi: 10.1590/S151680342010000400006

Sguissardi, V., \& Silva Júnior, J. dos R. (2009). Trabalho intensificado nas federais: Pós-graduação e produtivismo acadêmico. São Paulo, SP: Xamã.

*Silva, E. P. (2015). Adoecimento e sofrimento de professores universitários: Dimensões afetivas e ético-políticas. Psicologia, Teoria e Prática, 17(1), 61-71. doi: 10.15348/19806906/psicologia.v17n1p61-71

*Silva, J. L. L., \& Souza, S. L. de. (2004). Fatores de risco para hipertensão arterial sistêmica versus estilo de vida docente. Revista Eletrônica de Enfermagem, 6(3), 330-335. doi: 10.5216/ree.v6i3.838

*Silva, R. da. (2006). Características do estilo de vida e da qualidade de vida de professores do ensino superior público em educação física. (Tese de Doutorado). Universidade Federal de Santa Catarina, Florianópolis.

*Silva Júnior, J. dos R., Lucena, C., \& Ferreira, L. R. (2013). Mundialização e o trabalho do ser social professor pesquisador. Educação, 38(3), 483-494. doi: 10.5902/198464448985

*Soares, R. J. de O., Zeitoune, R. C. G., Lisboa, M. T. L., \& Mauro, M. Y. C. (2011). Fatores facilitadores e impeditivos no cuidar de si para docentes de enfermagem. Texto \& Contexto Enfermagem, 20(4), 758-765. doi: 10.1590/S0104-07072011000400015

*Sousa, A. M. de. (2013). O perfil do adoecimento docente na Universidade de Brasília de 2006 a 2011. (Dissertação de Mestrado). Universidade de Brasília, Brasília.

*Stehling, M. M. C. T., Rezende, L. do C., Cunha, L. M., Pinheiro, T. M. M., \& Haddad, J. P. de A. Oliveira, P. R. de. (2015). Fatores de risco para a ocorrência de acidentes em laboratórios de ensino e pesquisa em uma universidade brasileira (2012). REME, 19(1), 101-106. doi: 10.5935/1415-2762.20150009

*Tavares, J. P. (2010). Distúrbios psíquicos menores em enfermeiros docentes. (Dissertação de Mestrado). Universidade Federal de Santa Maria, Santa Maria.

*Tomé, A. C. N., Canello, T. B., Luna, E. J. de A., \& Andrade Junior, H. F. de. (2013). Health problems awareness during travel among faculty members of a large university in Latin America. Preliminary report. Revista do Instituto de Medicina Tropical, 55(1), 55-59. doi: 10.1590/S0036-46652013000100010

Ursi, E. S. (2005). Prevenções de lesões na pele no perioperatório: Revisão integrativa de literatura (Dissertação de Mestrado). Universidade de São Paulo, São Paulo. 
*Vilela, E. F., Garcia, F. C., \& Vieira, A. (2013). Vivências de prazer-sofrimento no trabalho do professor universitário: Estudo de caso em uma instituição pública. REAd - Revista Eletrônica de Administração, 19(2), 517-540. doi: 10.1590/S1413-23112013000200010.

*Xavier, F. dos A., Barboza, L. F., Monteiro, A. M. P., Santos, L. C. dos., \& Oliveira, D. R. de. (2010). Fatores de risco cardiovascular entre docentes de uma universidade pública de Minas Gerais. REME, 14(4), 465-472.

\section{AGRADECIMENTOS}

Agradecemos ao Programa de Pós-Graduação de Educação da Universidade Federal de Mato Grosso do Sul - PPGE/CPAN.

\section{CONFLITOS DE INTERESSES}

Não há conflitos de interesses.

\section{SOBRE OS AUTORES}

Franciele Ariene Lopes Santana é psicóloga pela Universidade Federal de Mato Grosso do Sul, especialista em Gestão em Saúde pela Universidade Estadual de Mato Grosso do Sul e mestre em Educação pela Universidade Federal de Mato Grosso do Sul. Coordena o Serviço de Psicologia e Acessibilidade Pedagógica (SEPAP) do Campus do Pantanal e o Grupo de Estudos, Pesquisa e Intervenção em Psicologia em Espaços de Educação e Trabalho (GEPIPET).

E-mail: franciele.santana@ufms.br

\section{(1) https://orcid.org/0000-0002-3931-1493}

Ilidio Roda Neves é psicólogo pela Universidade Estadual Paulista Júlio de Mesquita Filho, mestre Saúde Coletiva pela Universidade Estadual de Campinas e doutor em Psicologia Social pela PUC/SP. Coordena o Grupo de Estudos e Pesquisa em Saúde Coletiva e do Trabalhador (GEPSC\&T) e é membro da diretoria da Associação Brasileira de Psicologia Social (ABRAPSO).

E-mail: ilidio.neves@ufms.br

(1) https://orcid.org/0000-0002-4702-6668

${ }^{1}$ Para a clareza da Tabela, trabalhos com três autores ou mais foram grafados com "et al." já na primeira citação.

${ }^{2}$ Artigos demarcados com o símbolo * fizeram parte da revisão integrativa. 